\title{
A Theodicy of Kenosis: Eleonore Stump and the Fall of Jericho
}

https://doi.org/10.1515/opth-2020-0101

received April 2, 2020; accepted October 5, 2020

\begin{abstract}
When Joshua came to Jericho and encountered the captain of the LORD's host, his stance appears much like the theodicist, who, facing the awful prospects of suffering, evil, or death, seeks assurance from God, asking, "are you for us or our adversaries?" (Jos 5:13). Yet the angel's reply is not "yes," as typical theodicies seek to answer on God's behalf, but "No; rather I indeed come now as captain of the host of the LORD.” (Jos 5:14) The implication is political: the angel seeks to alter Joshua's stance from one ordered to his own purposes to one ordered to the LORD's. Like traditional theodicies, Eleonore Stump's Wandering in Darkness (2010) does not sufficiently establish why a theistic God must create a world where, to preserve our capacity to freely love God, suffering is caused or permitted. I avoid this problem by finding a "kenotic" aspect in the action of signs in which the perennial problems of suffering and evil do not arise, and which is available to direct experience, making it empirically falsifiable in principle. Like the angel's reply to Joshua, this invites a change from a speculatively grounded stance representing the hopes of a theodicist, to one formed from real interactions that transcend discourse.
\end{abstract}

Keywords: metaphysics, theodicy, problem of evil, sign action, kenosis, problem of suffering, John Poinsot, Eleonore Stump, real relations, Franciscan knowledge

\section{Introduction}

The theory presented in this article began, for me, with a startling closing stanza from E. E. Cummings.

Time's a strange fellow;

more he gives than takes

(and he takes all) nor any marvel finds

quite disappearance but some keener makes

losing, gaining

- love! if a world ends

more than all worlds begin to (see?) begin ${ }^{1}$

Reading this over the course of the death of my grandmother, I experienced a dramatic change of perspective on death and suffering that Eleonore Stump terms "Franciscan knowledge" 2 - an intuitive, perspectivegiving, right-brain knowledge-of something. This is opposed to a left-brain "knowledge-that," which typically attains the details of something and perceives its parts, but not the whole. It occurred to me

1 Cummings, Complete Poems 1904-1962, 750.

2 Stump, Wandering in Darkness, ch. 3, esp. 49-51.

\footnotetext{
* Corresponding author: Arlyn Culwick, Independent Researcher, Cape Town, Republic of South Africa, e-mail: academic@arlynculwick.com
} 
that E. E. Cummings' poem suggests a novel resolution to the often-confusing experience of suffering or death, by implying the idea that death is intrinsically part of love. ${ }^{3}$ At a later point, I came to realise that my principal object of study, the action of signs, empirically supports precisely this interpretation, which, if it were to be employed in a theodicy, would give it an epistemic advantage over traditional speculatively grounded theodicies.

Moreover, it appears to me that this novel idea can avoid a perennial problem that the traditional theodicies run into, which Stump has described ${ }^{4}$ as an "inconsistent set," namely an apparent inconsistency between maintaining God's goodness, omniscience, and omnipotence, human free will, and the realities of suffering, death, or evil. The theodicies of Augustine of Hippo, ${ }^{5}$ Thomas Aquinas, ${ }^{6}$ C. S. Lewis, ${ }^{7}$ Richard Swinburne, ${ }^{8}$ Alvin Plantinga, ${ }^{9}$ and, most proximally to this article, Eleonore Stump's Wandering in Darkness, ${ }^{10}$ do not establish why a theistic God must create a world where, to preserve our capacity to freely love Them, ${ }^{11}$ suffering is caused or permitted. I believe that it is possible to resolve this apparent inconsistency, and not merely by making the relatively trivial move of modifying the meaning of "goodness," "free will," "evil," or some other term on merely speculative grounds, but rather finding falsifiable empirical grounds for such a modification.

There is, furthermore, a moral or perspectival reason to make such a modification. Stump's illuminating work on "Franciscan knowledge" led me to wonder whether traditional theodicies effectively take the stance of Joshua when he comes to Jericho and encounters the captain of the LORD's host, and asks him. "are you for us or our adversaries?" (Jos 5,13) ${ }^{12}$ Yet the angel's reply is not "yes," as theodicies typically seek to answer on God's behalf, but "No; rather I indeed come now as captain of the host of the LORD." (Jos 5,14) The implication is political: while Joshua comes to the encounter with a question reflecting his own concerns, the angel's reply carries an implicit injunction that Joshua alter his stance to one ordered to serving the LORD. Now just as the appearance of the captain of the LORD's host transforms Joshua's stance, I think that the stance of a sincere enquirer would be similarly transformed by a messenger of another sort, namely the presence of empirically verifiable realities that attest to the need to modify our hitherto speculative conception of goodness. Specifically, I intend the theodicy presented in this article to function as "Franciscan knowledge" to adjust our stance from one of firstpersonal concern to resolve a problem, to a second-personal stance ordered to God by direct experience.

Concerning the directly experiential ground of this argument, I introduce the action of signs, which is directly experienced, and then defend an interpretation of it as exhibiting a "kenotic" aspect. If this interpretation is correct, then "kenosis" (self-sacrificial "love") is pervasive, and so a self-sacrificial aspect is pervasively part of the universe. (Particular attention will be given to how kenosis includes, as a part, our working self-sacrificially to modify where, and how much, suffering is borne.) This semiosic

3 A reader accustomed to the arid style of contemporary philosophical writing may perhaps find this "Franciscan knowledge" dubiously relevant background information that would better be abstracted from the presentation. However, the better part of this article is a "Franciscan" exposition, and this is also my principal use of Stump's work. Its nature and importance in theodicy will be shown in a subsequent section.

4 Personal communication with Eleonore Stump following the first presentation of this article, 20 July 2019.

5 C.f. Augustine of Hippo, Enchiridion: On Faith Hope, and Love, Chapter IV, and City of God, Chapter 17.

6 Aquinas, Summa Theologia, principally ST 1a, q. 48, a. 1-3. See also ST Ia, q. 22, a. 2. ad 2; ST Ia, q. 47, a. 2; ST Ia, q. 49, a. 1-3; ST II, q. 85, a. 6.

7 Lewis, The Problem of Pain, 47-8.

8 Swinburne, Providence and the Problem of Evil.

9 Plantinga, God, Freedom and Evil.

10 Stump, Wandering in Darkness.

11 It strikes me that God's trinitarian nature suggests an elegant way to avoid the use of inappropriately gendered pronouns: one may simply use "They." Since God is trinitarian, "they" does not run afoul of the experience, for some, that the pronoun is depersonalisingly plural.

12 If not noted otherwise, the biblical quotations follow New American Standard Bible. 
perspective evinces a world continually acquiring being, and compounding its perfection, through kenosis.

This article consists of three principal sections. In Section 2, I present the problems to be solved, namely the problems of suffering and of evil, and some attendant issues. In Section 3, I present a metaphysics implied by the action of signs, along with a brief introduction to sign action itself. I then use this exposition in Section 4, where I introduce kenosis, and defend the solutions it implies to the problems given in Section $2 .{ }^{13}$

\section{The problem of suffering and the problem of evil}

Theodicies well-known to contemporary philosophical readers include those of Thomas Aquinas, ${ }^{14}$ C. S. Lewis, ${ }^{15}$ and Richard Swinburne. ${ }^{16}$ They share a common attribute: they rely on the notion that human goodness (or, more specifically in some, for humans to love God) requires the exercise of free will. On these accounts, free will involves the potential to choose what is not good, and from this, evil, death, or suffering are said to provenate.

What stems directly from this construction are the commonly named problems of evil and suffering, which come down to the notion that if God were to permit human freedom, then They must unavoidably permit the privation of good; but this thrusts the theodicist onto the horns of a dilemma: on the one hand, it entails that God would be unable to create a world without evil, which appears to be a limitation of Their power. Alternatively, if one maintains God's omnipotence and argues that They permit evil, then it appears

13 Before moving on from the introduction to this article, it will be important to some readers to note that it is an answer to a "big question" and thus makes grander or more sweeping claims than is typical of papers in the analytical style. As my erstwhile supervisor is fond of saying (only half in jest), "we are professionals; we can write on any topic, at any length.” But no length is sufficient to bulletproof a Franciscan picture against counterargument. Moreover, a treatment of practically any length is capable of conveying a Franciscan picture, at least in essence. Hence, it is the limitations of the publication, not the "size" of the question, that determine the appropriate level of detail. As such, this article deals with certain matters more briefly than is currently customary, employing in places "Franciscan knowledge" to impart a perspective rather than specifying it analytically. This approach may come across to some readers as surprising or even ad hoc in places, especially since the better part of this article presents a novel view of the universe. But this is not due to a weakness in the argument (where it is a Franciscan picture, at least), it is an effect of experiencing something unfamiliar. I assure the reader that if the article appears to contain diverse topics, they are without exception engendered by either the nature of sign action, or the problem of theodicy itself. As for the need for such Franciscan approaches, all topics of philosophical value deserve a place, and for as long as the tendency to atomise is a strong current in contemporary philosophy, I believe the need is all the greater to focus on comparatively neglected "Franciscan," perspective-giving or synthesising work, and equally, there is a need for rigorous discussion about perspectives themselves, which is valuable in its own right and necessary if we are to elevate perspective-giving work (which often lacks rigour) above mere idle speculation. The situation may be considerably worse than a mere leaning toward atomisation, too: the very activity of philosophising appears to be compromised by the contemporary Anglo-American tendency to atomise. My impression of typically analytical papers is all too frequently that they sacrifice the activity of philosophising in favour of the merely scholarly tasks and technical methods attendant upon philosophising. By "philosophising" I mean directly the activity of finding answers to various questions, including and perhaps especially the synthetic task of finding answers that do not engender inconsistencies, contradictions, or paradoxes in other areas of inquiry. To philosophise, therefore, is necessarily creative and synthesising, over and above the requirements of good scholarship and of arguing soundly from premises to conclusion. But in my experience these latter activities very often overshadow the activity to which they are ordered, namely, "finding answers." Now since I think that this is a widespread practice, it appears to me that the greater value of philosophy itself is perhaps sacrificed in favour of a focus on micro-details and on tackling narrowly focused problems upon which one's technical skill may be well executed. In its pure form, the problem is that the ends are bent to serve the means, and not vice versa.

14 Aquinas, Summa Theologia, principally ST 1a, q. 48, a. 1-3. See also ST Ia, q. 22, a. 2. ad 2; ST Ia, q. 47, a. 2; ST Ia, q. 49, a. 1-3; ST II, q. 85, a. 6.

15 Lewis, The Problem of Pain, 47-8.

16 Swinburne, Providence and the Problem of Evil. 
that God cannot be perfectly good. In short, the "problem of evil" is a dilemma in which either God's omnipotence or omnibenevolence is at stake.

\subsection{Logical impossibility: a modal failure}

Richard Swinburne attempts an escape from the problem of evil, which he terms the "free will defence." 17 Swinburne proposes that, firstly, it is logically impossible for there to be both free will and no possibility of evil, and secondly that it is no affront to God's omnipotence to deny They have the ability to do logically impossible things. Hence, God is said not to be limited by being incapable of logical impossibilities. ${ }^{18}$

Now this escape may appear plausible because it is self-evidently beyond the power of human reason to conceive of logically impossible scenarios, and so it would be unreasonable to expect that God meet demands we cannot even articulate consistently. However, Swinburne's appeal to logical impossibility is a doubleedged sword that I believe defeats his escape. To deny God the capacity to act in logically impossible ways is to impose our mere experiential limitations onto God's nature. To be clear, I grant that we are not capable of conceiving of logically inconsistent scenarios, and so we certainly could not predicate of God a logically impossible act. Yet this offers no grounds to argue that God in his own nature is limited by logical necessity. As the creator of the universe, God would be the author of the "logic" delimiting the scope of our understanding, but there is no reason to suppose God is intrinsically limited by it. Thus, to project onto God a solution to a dilemma constructed in terms of the limitations of human understanding cannot succeed.

My objection here, unlike Swinburne's argument, does not cut both ways, and it does not deny or attribute powers to God. Rather, it notes an oversight in Swinburne's own proscription of the logically inconsistent. Specifically, limiting discourse to the logically possible not only limits what can be predicated of God (a positive proscription), but it also defines negatively what cannot be predicated of God, namely Their being subject to the logical limitations of our natures, when it is not known that God's nature is thus limited.

Now a failure of Swinburne's "free will defence" strengthens the attack on theodicy, because God's transcendence of the limits of our understanding, along with Their omnipotence, implies that God is quite capable of having created in us a different "logic" and a different state of affairs, in which the problem of evil simply does not arise. Why then has God not done so? The contention of this article is that this question arises - and can do so with considerable force when we are presented with grave suffering or evil - due to the concepts underlying it being speculatively derived, while if empirically verifiable realities are taken into account, the question would not arise because we would have the means to make sense of evil.

\subsection{The problem of suffering in Wandering in Darkness}

Eleonore Stump's defence against the problem of suffering takes a markedly different approach to that of Swinburne and others, in that while others tend to appeal to various intuitively hard-to-dispute features to support a resolution of the "inconsistent set," Stump develops a far richer world irreducible to any one set of features. This she terms "Franciscan," in contrast to an analytic or "Dominican" approach. Regarding the role and need for Franciscan knowledge in philosophical questions, Stump observes that, ${ }^{19}$

17 Ibid., "The Free-Will Defence" in Ch. 2.

18 For example, on page 3 (ibid.), Swinburne states that "An omnipotent being is one who can do anything logically possible, anything, that is, the description of which does not involve a contradiction: such a being could not make me exist and not exist at the same instant." Swinburne takes the same approach on the matter of omniscience, stating on page 6 (ibid) that "if the agent is also omniscient, he will know all the consequences of his actions which it is logically possible for him to know.” A theistic God, under Swinburne's treatment, is limited by logical possibility.

19 Stump, Wandering in Darkness, 23-5. 
The contemporary philosophical debate in Anglo-American philosophy over the problem of evil has become complicated and technical. [...] In its focus on such philosophical technicalities as the appropriate patterns of probabilistic reasoning, it seems simply to sidestep much that has been at the heart of the problem of evil for many reflective thinkers. [...] It is [...] misleadingly imprecise, [however], to diagnose the weakness of analytic philosophy as its narrowness. Its cognitive hemianopia is its problem. Its intellectual vision is occluded or obscured for the right half of the cognitive field.

Stump here refers to the "amateur but accurate neurobiological concepts" of the division of labour between the left and right hemispheres of the brain. "The practices of Anglo-American philosophy" exemplify the left-brain skills of "an attention to analytic detail and a predilection for precision," ${ }^{20}$ but this excellence "also has the vices of its virtues."21 Stump suggests that these vices are perhaps best avoided by "bolstering [Anglo-American philosophy] with the cognitive virtues embodied in other intellectual endeavours" by "marry[ing] it to the study of narrative." 22 In her view, the most workable way to do this, that is, without either reducing the use of narrative and exegesis to merely decorative, gratuitous use in the manner of "pictures put next to the text for those who find books without pictures boring," ${ }^{23}$ or by compromising the tight argumentative structure of analytical philosophical writing, is to do so antiphonally, that is, by inserting illuminating narrative passages at salient points in the analytical discussion. This allows "a narrative [...] to be considered in its disorderly richness [, and] once it has been allowed into the discussion on its own terms, philosophical reflection enlightened by the narrative can proceed in its customary way." 24

As for what specifically is at the heart of the problem, and which analytic philosophy is perceived to be prone to miss, I find Ryle's concept of "thick description" illuminating. ${ }^{25}$ In contrast to "thin" description, thick description includes not just a direct or object-level description of something, but also its context, especially as understood by people to whom the context is native ground. Echoing Clifford Geertz's use of thick description, ${ }^{26}$ Stump's 1985 paper, "The Problem of Evil" ${ }^{27}$ embodies a striking distinction between the "thin" theodicies of Swinburne, Plantinga, and Hick and the "thick" alternative she proposes. Under the "thin" theodicies, the premises of the inconsistent set - (1) God is omnipotent; (2) God is omniscient; (3) God is perfectly good; and (4) There is evil in the world - look inconsistent. However, by supplying a "thick description" of how at least a broad subset of Christians have traditionally contextualised these premises, Stump makes a case that the inconsistency does not arise, at least on grounds that while the additional premises which emerge from Stump's thick description are not demonstrably true, they are at least defensible. ${ }^{28}$

As such, the primary argumentative thrust from premises to conclusion available to opponents of "thin" theodicies is unavailable in the context of Stump's "thick" theodicy. This is due, in Stump's view in Wandering in Darkness, to the use of narrative to supplement the "left-brain" virtues of analytical philosophy with context- and perspective-giving "right-brain" insights. With such supplementation, her treatment of the subject is intended to avoid "sidestep[ping] much that has been at the heart of the problem," and to render the problem more truly and completely - and of course this exercise makes available a new candidate solution to the problem.

The better part of this article makes use of thick description for the same purpose: in order for my conclusion to follow, it is required that a certain view of the universe be given, namely a universe composed entirely of sign relations. To evoke this view (and in addition to persuade the reader of its reality) it must be described "thickly" in order to enable the reader to understand the subject not only analytically but also in

\footnotetext{
20 Ibid., 24.

21 Ibid., 23.

22 Ibid., 25.

23 Ibid., 26.

24 Ibid., 27.

25 Ryle, “The Thinking of Thoughts: What is 'Le Penseur' Doing?”

26 Geertz, "Thick Description: Toward an Interpretive Theory of Culture.”

27 Stump, "The Problem of Evil," 392-424.

28 Ibid., 405.
} 
Stump's "Franciscan" manner. Without the latter, it is exceedingly unlikely that the reader will have the necessary insight or perspectival realisation of the whole picture, over and above its parts, to be able to follow the argument from premises to conclusion.

\subsubsection{Stump's strategy against the argument from evil}

Stump makes use of Franciscan knowledge to illuminates the problem of suffering in such a way that (with many qualifications) it does not arise in at least one possible world - namely, the world evoked in several extended reflections upon the biblical narratives of Job, Samson, Abraham, and Mary of Bethany. ${ }^{29}$

In this possible world, Stump argues for the defensibility of Aquinas's theodicy, ${ }^{30}$ and on page 415, notes a possible objection which bears upon my objection to Swinburne. The objection Stump notes ${ }^{31}$ is that

there is a best of all possible worlds, and a perfectly good God has an obligation to create or produce it. But [the world we live in] is arguably not the best of all possible worlds. And so [...] even if Aquinas's attempted theodicy is otherwise successful, the problem of suffering simply arises again in a different guise.

My objection to Swinburne's argument in the preceding paragraphs has the same upshot as this argument, which is that a theistic God cannot have created the actual world. After all, if a theistic (that is, omnipotent, omniscient, and perfectly good) God is unlimited by our understanding of logical possibility, then They cannot be supposed to be limited in any thinkable way from creating a world in which suffering and evil do not exist. Now while my version of this objection may be more difficult to defeat than the one Stump responds to, it remains true that ${ }^{32}$

the main problem with the objection [...] is that it disregards the dialectic of the discussion. The proponent of the argument from evil claims that it is not possible for there to be a world that is like the actual world as regards suffering (and other related empirical facts) and that nonetheless also contains an omniscient, omnipotent, perfectly good God.

That is, successful theodicy neither need defend the claim that our world is the best of all possible worlds, nor deny that a theistic God is obliged to create the best of all possible worlds. Rather "the challenge posed by the argument from evil is to show that there could be such a God in a world like ours." 33 This is the rationale behind Stump's defence, and, I believe, a key contribution to the discourse on theodicy: to provide Franciscan knowledge that illuminates the problem in such a way as to reveal a possible world in which both evil and a theistic God exist.

\subsubsection{The cogency of a speculatively grounded theodicy}

However, Stump intentionally evokes a merely possible world by appealing to narratives where the moral of their stories are not empirically verifiable. It does not appear that an appeal to a possible world can produce a strongly compelling argument, especially to those already invested in a position like the above objection to Swinburne. Even if it is accepted (as I accept) that the objection is constructed upon speculatively grounded premises, it is rather seldom that one abandons a commitment to a possible world in favour of another possible world. After all, possible worlds are things that people entertain, a major part of which is pursuing potential ways to enrich them - which in this case involves better establishing their reality. To abandon the pursuit of a possible world which one is invested in, in favour of another merely possible world, appears unlikely. It is akin

29 Stump, Wandering in Darkness, Part 3 (Chs. 9, 10, 11 \& 12 respectively).

30 Ibid., 370-417.

31 Ibid., 415.

32 Ibid., 414-5.

33 Ibid., 214. 
to coaxing a fan of Star Wars to instead become a fan of Star Trek on grounds of its greater scientific realism. Far from recanting their commitment, one can expect the fan to defend their investment by extolling the virtues of Star Wars. Analogously, those committed to the objection against Swinburne can be expected to reason, for example, that it commands greater allegiance, on account of its simplicity and clarity. Why would a theistic God (unlimited even by the human-relative limits of logical possibility) resort to creating a world such as the one Stump evokes, with its many vagaries, instead of effortlessly creating something undeniably free of evil or suffering?

Now it is possible that no theodicy will have a direct answer to this question. However, theodicies (such as the one in this article, and in Stump's book) do attempt to draw the objector from their speculatively grounded position toward another position. But the cogency of the attempt will be profoundly affected by whether the alternative view offered is no less speculatively grounded than the objector's, or is empirically verifiable. ${ }^{34}$ It is to the latter that I attempt to draw my readers.

Finally, in addition to the merely possible nature of the world that Stump would draw her readers to, she makes no claim for its success simpliciter, qualifying and limiting her position in many respects. In this vein, Paul Draper notes ${ }^{35}$ four problems with Eleonore Stump's theodicy, namely that it is difficult to see how Stump's argument accounts for (a) suffering which predictably diminishes the sufferer or (b) natural disasters that indiscriminately affect people, when the healing of individual psychological fragmentation is the goal of suffering on Stump's account; (c) how trivial suffering (like scraping one's shin) could aid sanctification; and (d) why humans and animals suffer similarly, when animals seem incapable of undergoing a process of justification and sanctification. I claim to avoid these problems arising through the generality of the approach to be taken in this article, in contrast to the strategy of appealing to specific goods that suffering may present for the sufferer (in Stump's case, for example, healing psychological fragmentation, or aiding sanctification). A fully general account of the role of suffering and evil may avoid specious problems because genera function to allocate a place for their species. For clarity, the type of generality invoked here is not a category or a universal, but a fundamental mechanism amenable to empirical verification.

\section{A new approach}

With our predicament and method thus defined, the principal task of this article is to introduce a perspective under which the problems of suffering and of evil do not arise. Such a perspective, I will argue, is implied in the nature of sign action, a phenomenon that is not only a universe-wide and fundamental physical activity, but is also available to direct experience, making it amenable to empirical methods. Note, however, that even if this perspective were expounded upon at book length, there would remain innumerable potential explanatory gaps, perplexities, and refinements available to critics. Such is the nature of any "Franciscan" picture: it evokes a complex whole instead of a mere collection of parts, and its employing of our "right-brain" ability to transcend mere "knowledge that" and instead to know or become acquainted with a thing itself, ${ }^{36}$ is its principal strength, not a weakness. This would, however, be a weakness for my argument if its foundation, sign action, was not amenable to empirical verification, but this is not the case.

A defining aspect of sign action, which I term "kenosis," will do the heavy lifting in accounting for suffering and for evil. Its fundamentality and pervasiveness are of principal significance, since if kenosis were not pervasive or fundamental, then there would be some other activity which I might

34 See footnote 71 for distinctions between speculatively grounded ideas, empirically verifiable hypotheses, and verified or scientifically known theories.

35 Draper, “(Review) Wandering in Darkness: Narrative and the Problem of Suffering.”

36 Stump, Wandering in Darkness, 50. 
also need to account for before the problems of suffering and evil could be said not to arise. As such, I will need to begin in the broadest terms, exploring the relational nature of the universe, then exploring the nature of relations, then observing the respect in which the action of signs is "kenotic," and finally to explaining how the kenotic nature of the universe resolves the problems of suffering and evil. The exposition begins speculatively; later, the grounds upon which it is rendered empirically testable are given.

\subsection{Universes}

Consider the following thought experiment: imagine a collection of objects, none of which can have any kind of relation to each other. In order to construct this experiment correctly, do not attempt, in one breath, to visualise a collection of objects that can have no relation to each other. Rather, by a process of abstraction begin to consider such a scenario, and as soon as you think of any respect in which the objects might be related, rule it out. Are they related in space? No. Do they both have shape? They could not. Do they both have a surface? No. And so forth.

Now in what respect could these objects comprise a system? In no respect, since there is no means by which the objects can be related. There would be nothing over and above their existence by which they could comprise a system. Hence, universes necessarily are systems, however scantily related their components might be, or else there would be nothing to make a universe an entity in its own right, over and above its components. If one were to argue the contrary, the only basis by which a universe could be anything would be by force of describing it in language or in thought. As such, however, it would be a mere nominalism. Without a mind-independent basis intrinsic to the universe in question, there would be no way in which a universe could be anything in its own right.

\subsection{Objects necessarily are systems too}

Let us now turn our focus onto the objects themselves in the thought experiment. For anything to be an object, it would have to be a system of interactions in its own right. If you are in any doubt about this, it appears to be the case for the actual universe. The body of scientific theory implies that any given object reduces to relations "all the way down." For example, this seems to occur in physical sciences, which reduces "matter" to relations pervasively:

(1) A theory - say, gas laws - explains (and predicts the behaviour of) an object or system of objects in terms of relations between aspects, components, or attributes it has (in the case of gas laws, molecules).

(2) Since relations necessarily have terms, the objects or systems embodying these terms are then empirically investigated, resulting in a theory that describes their internal relations. For example, molecules are in fact relations between atoms or ions.

(3) These new relations' terms (i.e. the atoms) are investigated, resulting, of course, in a further theory that describes the behaviour and constitution of the object in question in terms of further relations between new terms, ad infinitum.

(4) Thus, gases are relations between molecules, which are relations between atoms, which are relations between electrons, protons, and/or neutrons, which are relations between quarks, leptons, and bosons.

The latter are called "fundamental" particles not because they are known to be indivisible "building blocks" of reality, but merely because it is unknown whether they have parts in relation. It is possible that at smaller scales there are no further parts or "particles" (that is entities identifiable by spin, energy level, etc.) - for example, it is typically thought that electrons have no component parts. This is not to say, however, that there would be nothing; at the most fundamental layer, there would be something - perhaps simply a vague fuzz of relations between relations, with no term having intrinsic specification (an intrinsic 
nature) of any kind. Such a scenario is theorised under the name "quantum foam" to be interspersed by particles (and their complimentary antiparticles) momentarily popping into existence and then annihilating themselves, giving spacetime a granular texture that otherwise would be "smooth," that is to say, having nothing to cause enough disturbance to quantise out a particle. This scenario suggests a thoroughgoing fundamental relationality at scales smaller than fundamental particles, where the universe lacks the stability to sustain a mechanism to produce objects reliably.

Now since our thought experiment is one in which there are no relations, it follows that it could contain no objects, since being an object requires having relations. Therefore, it can feature neither objects nor a universe. In other words, the scenario contains "nothing" at all.

\subsection{The fundamental primacy of relations}

From this we can conclude - to put it informally - that something is only something if it is something to something else. Apart from this, it cannot be actual. From the perspective of being a universe and not just a relationless "heap" ${ }^{37}$ there is no difference between there being no objects at all and each object being nothing to any other object: in either case the outcome is identical: since a universe requires some way of relating - some "principle of unity" - there would be no way to be a universe.

As such, relation is the defining feature of what it is to be a universe. By definition a universe is a kind of whole, a unity of parts; therefore, what defines a universe is not its parts, nor the sum of its parts, but the fact of its parts being related. And if objects are parts in relation too, then a universe just is relations. Therefore, relation is fundamental to the universe in the sense of it being the principle or form of universehood.

Furthermore, since physical objects are always constituted by relations, objecthood is always a kind of construct or composite. Hence, in terms of the constitution of things, real relations, by their simplicity, are more physically fundamental than objects, which are composite. ${ }^{38}$

\subsection{Being undetermined: order, chaos, and change}

To return to the nature of "nothingness," when constructed in the context of this relational metaphysics, it has properties that I will rely on later for establishing this theodicy, namely how respects in which things are related, in conjunction with respects in which things are unrelated ("nothingness"), can permit indeterminate interactions. A case of indeterminate interactions is one where interactions are possible, yet in one or more respect are minimally determined or undetermined. For example, fluctuations in the quantum vacuum, and some properties (e.g. spin) of entangled particles, are thought to be truly random..$^{39 \cdot 40}$ Now it appears that there is nothing to prevent the existence or even the prevalence of true randomness in a universe, and to manifest this, I will first clarify the difference between identity and relatedness.

37 It is a linguistic and mental fact that by thinking of things as being a "heap" they are thereby related in thought. However, this is to be taken strictly as an artefact of thought, with no bearing on the scenario itself.

38 This is a difficult area which cannot be adequately resolved in a few paragraphs. For example, this statement, on its own, would imply an eliminative regress for the term "object," since in my model, objects consist of parts in relation, and so they would reduce to further relations, all the way down, leaving no terms to found any relations. For full treatment of this subject, see Culwick, "Machine Code for the Universe."

39 A empirical proof of the randomness of properties of entangled photon pairs has been obtained by Pironio et al. "Random numbers certified by Bell's theorem."

40 An insightful plain-English introduction to the relation between entanglement and randomness is available at https://www.americanscientist.org/article/quantum-randomness. 


\subsubsection{A limit case of relatedness: identity, or total relatedness}

The distinction between identity and relatedness is defined by whether there are any respects in which things are unrelated. It is one thing to be related in some respect, it is quite another thing to be related in every respect. In the latter case, the two things would simply be one thing, because there could be nothing to individuate them from each other. As such, an object's distinctness from another object is modelled as there being at least one respect in which they are not related (Figure 1).

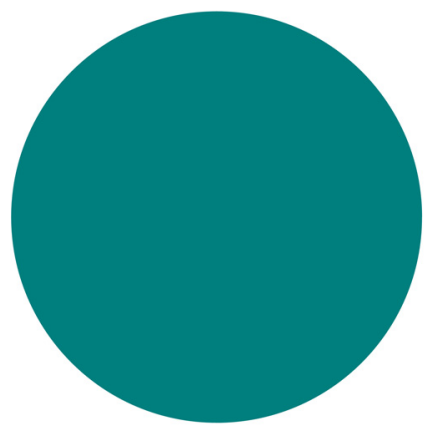

these two objects are related to each other in every respect

Figure 1: Identicality modelled in relational terms.

Now if things are not related in every respect, then there is at least one respect in which they do not determine each other. And if they do not determine each other in a given respect, then, contrary to the common view that order equates to determinism and thereby rules out the possibility of freedom, their relations in this respect are "free" or "accidental." This is to say that their interactions in this specific respect would be truly random. ${ }^{41}$

\subsubsection{Determinacy and freedom}

The fact of limited determinacy between objects thus defines the nature of randomness or chaos (of either the deterministic or absolute sort). Since a universe has, as its fundamental organising principle, that things are only something if they are something to something else, then necessarily every entity in the universe must participate in this organising principle. Such a principle is the minimal order required to be (in) a universe. But this entails that universes (and all their parts) fundamentally have order. Therefore, for a universe, order is more fundamental than chaos or randomness. Chaos is, at most, no more universal than the set of respects in which bodies in a system do not determine each other.

\subsubsection{Grades of indeterminacy}

The possibility of indeterminacy creates considerable scope for change to occur in an ordered universe, since any respect in which an object is currently undetermined could become determined if a new relation

41 I do not mean to suggest this as a solution to the problem of "free will," even though it is often sought for as if it would solve the problem. After all, to be undetermined is to have no reason to act, thus undermining what it means to will. Therefore, if human will is free, it would necessarily be in a different sense, such as that of being able to do what one wants to do. I recommend Powell's book, Freely Chosen Reality, on the topic of establishing a knowable (nonspeculative) respect in which humans are free. 
were to arise, which would thus constitute change. In fact, the potential for change could (theoretically) be measured or mapped using "grades of indeterminacy" or freedom: the more respects in which things do not determine each other, the higher the grades of freedom they have from each other. For example, an asteroid moving in space does not determine the direction or velocity of another asteroid (excluding, for the sake of argument, their tiny gravitational attraction), which is why it is acceptable to say that they can collide by "accident;" their motions are largely determined freely of each other (until they collide, of course). Moreover, other of the asteroids' attributes are entirely undetermined by each other's, like, say, their colour and the type of rock they are made of. Thus, even in a fully determinate Newtonian system, bodies are not determined in every respect but have freedom from each other (Figure 2).

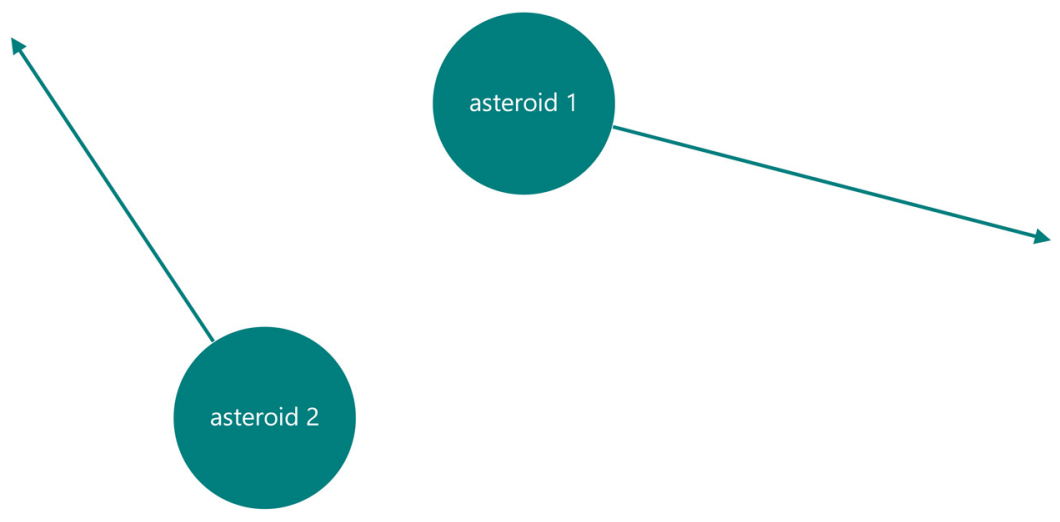

asteroids' velocities are indeterminate with respect to each other

(excluding, for the sake of argument, gravitational pull)

Figure 2: Indeterminate (free) motion in a determinate Newtonian system.

This freedom can become very great, as in the case of Brownian motion, in which no detectable pattern of behaviour obtains. The marvel of it, though, is that each moment of interaction follows deterministic principles of ballistics, ${ }^{42}$ yet the rich interplay between a particle and the medium it is in results in random motion. This behaviour even turns out to be easy to simulate..$^{43}$ Thus, on empirical grounds too, determinate systems that do not determine every respect in which objects have being leave these objects partly undetermined and thus potentially able to support new relations, making "space" for change to occur - sometimes to such an extent that randomness can manifest.

\subsection{What relating comprises}

With the nature of indeterminacy modelled relationally, it remains to expose some general properties of relations before the material required to articulate and defend this theodicy is available. What follows is a brief introduction to their nature as understood by philosophers in the longest period of sustained philosophical discourse on the subject (and by far the most technically sophisticated): second scholasticism.

Consider some object in real relation to another object. Formally speaking, the relation occurs between at least one attribute that each object has, and the attributes are required to be strictly correlated in order to

42 Huang et al., "Direct Observation of the full transition from ballistic to diffusive Brownian motion in a liquid."

43 E.g. http://www.phytools.org/eqg/Exercise_4.1/. 
relate in a given respect. For example, a relation of parenthood requires one person to possess the attribute of being a parent and another to possess the attribute of being a child. These are "terms" of the relation, and in scholastic parlance, the relation is "founded" upon the attribute of being a parent and "terminates" at the attribute of being a child. Recall also that no relation is actualised in a universe unless it affects something else; this requires that no relation is real unless some entity is affected by it. This (logically) third entity is termed by the scholastics a "knowing power." In the nineteenth century, Charles Sanders Peirce proposed a generalisation of the term to include mind-independent "powers," which are termed the "interpretant" of the relation. ${ }^{44}$ I shall rely on this concept henceforth (Figure 3).

We learn from John Poinsot ${ }^{45}$ that there are in fact two correlated facets to each relation between attributes. Since they are correlates in the same relation, they are one phenomenon and thus demand one name; I will show shortly that it is worthy of the designation "kenosis."

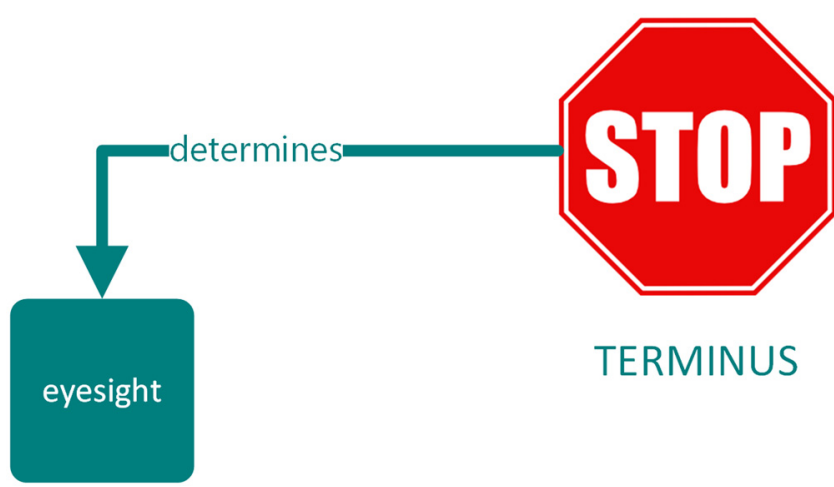

Figure 3: A relation of determining.

The first correlate is known as determining ${ }^{46}$ and is the role of a relation's terminus. For example, a stop sign cannot terminate the thought that it is rectangular, since it is octagonal. What a terminus does is delimit the scope of possible ways it may be related to. In this way, a terminus determines its fundament by having a certain nature, which cannot be what it is not, and so cannot support a fundament that is unable to relate to its attributes (Figure 4).

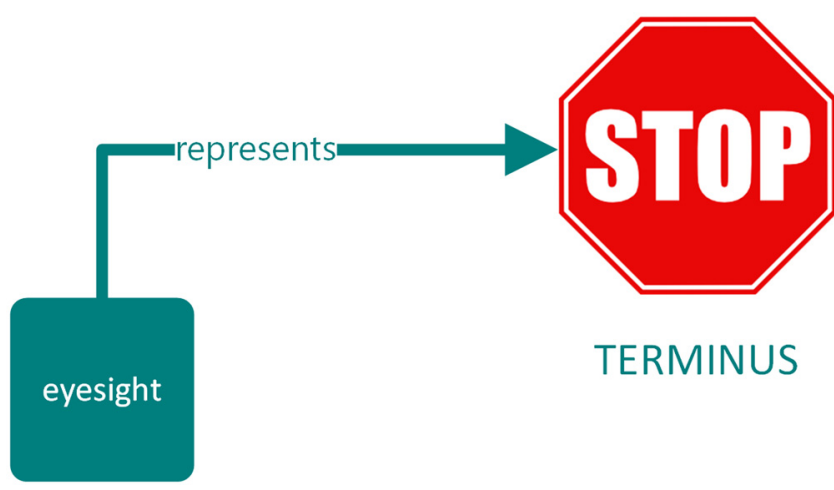

Figure 4: A relation of representing.

44 Peirce, Lowell Lectures on The Logic of Science; or Induction and Hypothesis: Lecture VII, W 1:464-5. 45 Poinsot, Tractatus de Signis.

46 Ibid., 166-92 (Book 1, Question 4). 
The second correlate is known as representing. ${ }^{47}$ It is the role of the fundament, and runs in the opposite causal direction to determining. For example, when you see a stop sign, your perception of it represents the octagonally shaped stop sign - and thus you are guided to recognise that it is a stop sign. In this way, fundaments represent their termini by having attributes that are taken - by some interpretant - to embody a terminus due to the terminus being taken to possess those attributes.

In every actual relation, determining and respecting occur together in a two-way causality, which I term founding. ${ }^{48}$ For example, after a driver has recognised a stop sign, it can function to found a relation to the rules of the road. It does so because the rules of the road determine the meaning of a physical stop sign, enabling the sign to represent the rules, and thus to signify to the driver the command to stop. These two facets of founding obtain between both a fundament and terminus, and between an interpretant and fundament, producing the triadic nature common to all real relations. ${ }^{49}$

Some further distinctions will be necessary. Imagine a driver who notes a stop sign and stops her car. Here, the driver is an interpretant, the stop sign a fundament, and the stopping of the car is the terminus of the relation. Now the stop sign has many attributes that do not contribute to its function of signifying the command to stop, for example, it is made of metal, it is 8 feet high, etc. The attributes that directly function to signify the terminus are the proximate fundament, while the remote fundament is the object to which the attributes belong. The terminus also has two aspects: one intrinsic to the relation and one extrinsic to it. The physical stopping of the car is the material terminus, while the purely formal respect in which stopping correlates to a command to stop is the formal terminus. Finally, the remote interpretant is the driver, and the proximate interpretant is the attribute(s) of the driver that function to interpret the stop sign (Figure 5).

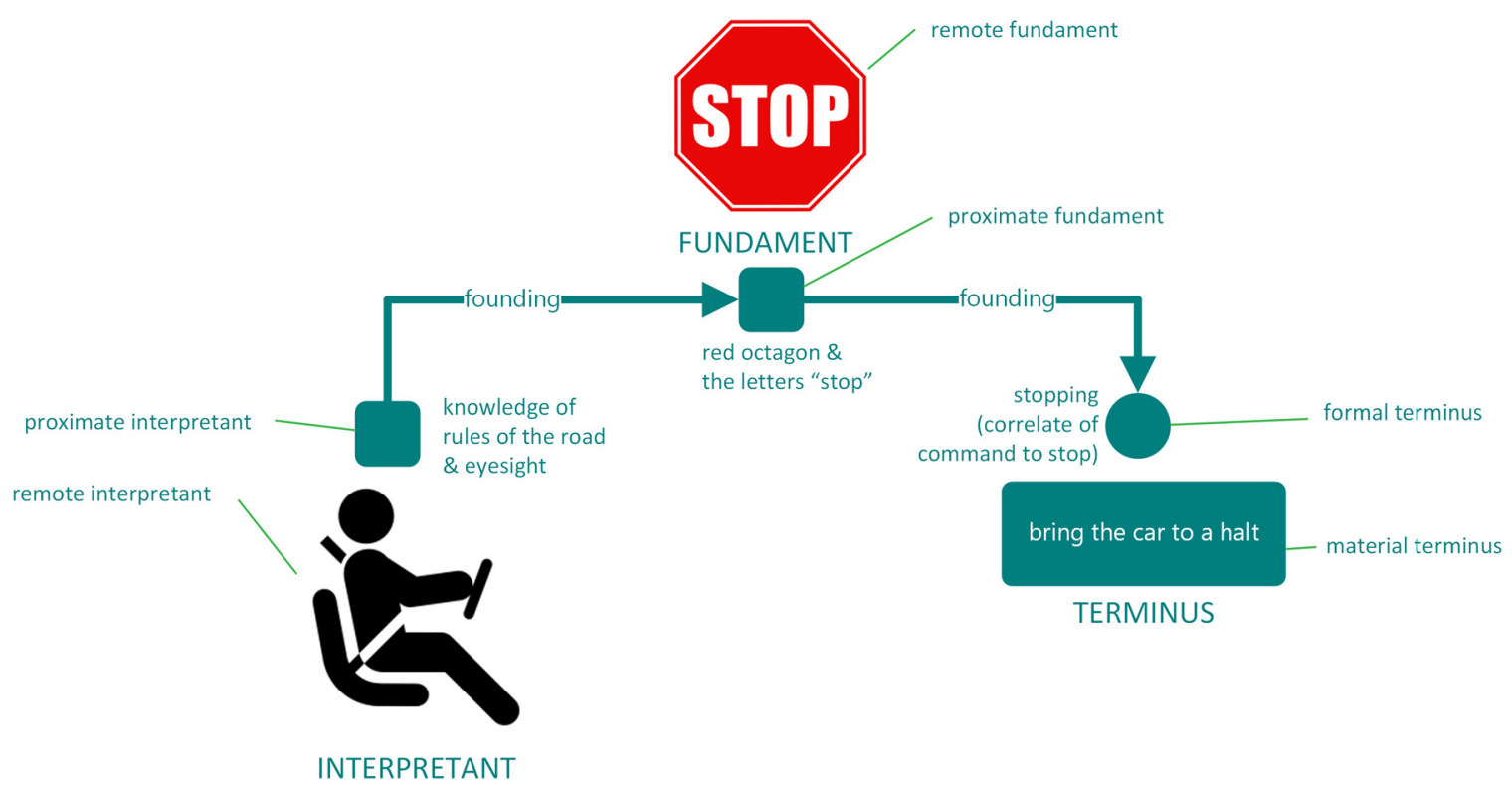

Figure 5: Signification in simple terms.

47 Ibid., 26 (Book 1, Question 3).

48 Culwick, "Machine Code for the Universe," 17.

49 And indeed common to all signs. (All real relations are signs, but not all signs are real relations.) For a more detailed introduction to the nature of real relations, see Culwick, "Machine Code for the Universe." 


\subsection{A layered universe}

In dramatic contrast to the reasonably popular notion that the universe can be modelled in a "flat" manner (e.g. using cellular automata), the earlier example concerning gas laws evinces a universe consisting of layers identifiable by objects' causal dependence upon systems at both larger and smaller scales. For example, the behaviour of a gas is determined both by properties of its molecules and by atmospheric pressure. Indeed, our understanding of the universe is that there exist broad physical regimes defined by scale, to which correspond distinct, layered scientific fields like quantum physics, chemistry, biology, psychology, and social science (loosely arranged in ascending order of scale).

Now layering is also clearly identifiable in the action of signs, and it will play a key role in the defence of this theodicy. It already follows self-evidently from the thought experiment on the nature of universes that the universe is a multivalent web of relations between things at different layers, where, whenever a set of relations comes to constitute an object to some interpretant, then this set of relations now also functions as a terminus or fundament of a further relation to the interpretant. This propensity to compound relatedness produces a universe not merely layered in a linear or hierarchical fashion, but one that is richly ordered with dizzying complexity, in a manner frequently indifferent to scale. ${ }^{50}$

To make head or tail of this multivalent ordering, some scheme is required. Fortunately for this theory, sign action itself supplies such a scheme, and I will employ the concept of an "abstraction layer"51 (borrowed from computer science) to describe it. An example of an abstraction layer is that when using a mobile phone, one does not enter lines of code; one instead simply presses buttons on the screen. This is the result of base-level code being interpreted in terms of an intended function or "purpose," which, in turn, determines the higher-level screen-tapping. That is, not only does screen-tapping utilise the base-level code, but it also orders it toward some purpose.

In the case of sign action, while the causality of a fundament upon an interpretant is the same as that of a terminus upon a fundament, fundaments are quite unlike termini, and exist at a higher layer of abstraction. To illustrate, if a terminus is brought into relation with an interpretant via a fundament, the terminus is not a mediator or "vicegerent" 52 of anything (at least not within this specific sign relation), but the fundament serves as vicegerent to the terminus. This entails that the "proximate fundament" - the attribute that represents the terminus - is not a simple attribute of the remote fundament taken in isolation, but is rather some higher-order attribute of the relation between the remote fundament and the terminus. For example, a red and white metal octagon is in no respect simply or intrinsically related to a command to stop, but when its physical properties serve to signify the command to stop, it functions as a stop sign. As such, a proximate fundament implies attributes of its terminus in a remote fundament, or, to put it modally, fundaments virtually include their termini. Now since a higher-order entity (a fundament) is always formed in signification, it follows that every sign establishes a new layer of reality. This, then may, in turn, become open to sustaining yet other relations, at other layers.

As such, sign action provides a low-level mechanism to account for the universe's observed prolific layering. By tracking the sign action in any given system, its causal dependencies may be uncovered and mapped at a fundamental level. In any case, the ability of sign action to articulate the multi-layered complexity observable in the universe will come to bear upon how this theodicy can incorporate suffering or evil, including "natural evils" such as random, trivial, or haphazard events, as will shortly be seen.

50 As is evident in, for example, the causal relation known as a "strange loop" (Hofstadter, I Am a Strange Loop).

51 The Computer Language Company Inc., "abstraction layer."

52 The canonical introduction of this term is given in Poinsot, Tractatus de Signis, 119137 (Book 1, Question 1). 


\subsection{Empirical verifiability}

The ability to test the theory of sign action empirically is of principal importance to this theodicy, since it is what distinguishes it from the merely speculative approach taken traditionally by theodicists. We owe it to Ralph Austin Powell for providing what I believe is a successful defence of scientific realism, without which empirical verification could not establish publicly verified realities, ${ }^{53}$ and for providing a suitable methodology for testing theories of the kind presented in this article. What follows is a brief exposition of Powell's approach. ${ }^{54}$

\subsubsection{Real relations are the principal object of scientific study}

In a 1989 paper, Powell observes that, on the historical evidence, real relations of a specific sort are the principal object of scientific study. Scientific method does not reveal the intrinsic nature of things: ${ }^{55}$ the effects predicted by science are of the nonmaterial, purely formal, nature of a specification of form (e.g. velocity, position, etc.) in future on the basis of data of a present state; but a future state such as this "lacks an intrinsic formal cause [and.] any intrinsic nature. Hence, temporal relations have only got extrinsic formal specification." ${ }^{56}$

Powell then elaborates on how real relations exhibiting extrinsic formal specification function in the growth of scientific knowledge: ${ }^{57}$

\footnotetext{
it is precisely the function of extrinsic formal causality to displace the agent and final causes by a more elementary cause. [...] Thus the solar system is explained as a mechanism specified by extrinsic formal causes without needing any explanation by agent causes (let alone by final causes which have not been recognized by science since the 17th century). For, Einstein's general relativity precisely eliminated gravitational forces [under the rationale of an agent cause] from explanation of the solar system, by substituting the curvature of space-time for gravitational forces..$^{58}$ Now gravitational forces are agent causes, whereas the curved space-time that governs the path of the earth around the sun is an excellent example of extrinsic formal causality.
}

In other words, scientific investigation involves a process where the agent causality of "material" bodies in an earlier theory is surpassed by a later theory employing extrinsic formal causes, on grounds that the latter is knowable and testable, while the former constructs the same object of experience along the lines of an unknowable intrinsic nature. As such, the employment of extrinsic formal causes permits the growth of scientific knowledge.

\subsubsection{Real relations are directly experienced}

In terms of the subjective foundation of our ability to make scientific observations of mind-independent realities, this would not be possible unless we are physically affected by real external things, and are thus passive to them. Powell observes that to be passively affected is to be in a causal relation of agent to patient, from which it follows that we directly and immediately experience these relations. ${ }^{59}$

53 In contrast, an antirealist philosophy of science, for example, denies that the scientific method can produce proofs about the nature of reality.

54 A fuller presentation is given in Culwick, "How To Render Freedom Empirically Verifiable: Ralph Austin Powell's Radically Scientific Thomism."

55 Powell, “Epistemology’s Minimal Cause as Basis of Science,” 183.

56 Ibid., 182-3.

57 Ibid., 186.

58 Hawking, A Brief History of Time: from the Big Bang to Black Holes, 29-30, in Powell, "Epistemology's Minimal Cause as Basis of Science."

59 Powell, "From semiotic of scientific mechanism to semiotic of teleology in nature," 299-300. 
To give an example, consider a glass of water in front of you. Pick it up, drink from it, use it. Your experience of the glass is not the immediate knowledge of things attributed to God, but rather one mediated by your senses. It is scientifically theorised that attributes of the glass - say, its reflection of light in various frequencies - serve to stimulate your visual system, the resulting electrochemical signals from which serve as grounds for you to perceive and cognitively identify the glass. That is, one is in relation to the glass. More significantly, it is the relation that you directly experience, whereas you do not directly experience the intrinsic nature of the glass itself (nor the theorised intermediate steps: the electrochemical signals and light frequencies). These can merely be inferred from what is implied by directly experienced relations. That is, experience of some relations is direct, whereas experience of the object requires the mediation of relations.

\subsubsection{The function of scientific tests is to distinguish real and unreal relations}

Powell then builds upon the direct experience of real relations a framework that may be exploited for the empirical verification of the nature of signs. This is a complex, book-length argument, which cannot be reproduced here, but its essence is intimately familiar to scientists: first, a hypothesis must be drawn that can in principle be falsified by observation. Second, a test must be devised that permits the confirmation or falsification of the hypothesis. Third, the test must produce a direct private experience for the experimenter, which confirms or falsifies the hypothesis. Fourth, the scientific community must be aware of the experimenter's potential responses to this private experience; in other words, the possible responses must be known public objects, that is, objects of common experience that are either fictitious or (at least in some respect) real. Fifth, members of the public must be capable of having private experiences of the public object of the experimenter's response, so as to be able to verify the response and thus learn what it implies.

The purpose of all of this is of course to gain knowledge, that is, not merely private ("subjective") experience, but publicly verified realities, so as to distinguish between unreal public objects and whatever reality there may be in them, or underlying them. As mentioned, Powell holds for the reality of (at least some) relations only. Now the way that scientific experimentation results in knowledge is that this private experiencing of public objects permits the experience of a new distinction between real and unreal relations. Powell gives an example: people hold differing views about real relations in society, like those "about relations of management and labour, or rich and poor, and of the well educated and the poorly educated." 60 Some of the differing views Powell cites are that for one group, loyalists, "these real relations, sanctioned by our legal system, are seen as inequalities inevitably resulting from the functioning of a free society." 61 However, another group, deviationists, hold that

at least a good part of these relations till now sanctioned by American law and taken for granted in American life should no longer be tolerated. Real relations long identified with legal order they now declare to be devoid of true legality. [That is, the] existing system of real relations is seen [to have merely] spurious and unreal legality. ${ }^{62}$

From this it can be seen that the two groups' differing views hold for the same underlying real relations of wealth inequality, education, and so forth. But in the absence of the deviationists, it would not be possible to establish as public objects, and distinguish, the real relations from the mere views or unreal relations of the loyalists, because without contrasting views, the revealed difference between real structures and unreal views would not be experienceable. ${ }^{63}$ Yet in the presence of these contrasting views, each view can now be seen to be identified with the real relation, for example, to the deviationists, spurious laws maintain real structural

60 Powell, Freely Chosen Reality, 92-3.

61 Ibid., 93.

62 Ibid.

63 Ibid. 
inequalities in society. The deviationists' activism consists precisely in differentiating real structural inequalities from unreal views codified in law. Moreover, this identification and differentiation makes it possible to experience them as distinct objects for the first time. And they are clearly public objects. Hence, what results is that we immediately experience public objects distinguished by their reality and unreality. ${ }^{64}$

To establish conditions for the falsifiability, thus the scientific legitimacy, of my theory of signs, what remains is for Powell's framework to be applied to it. This is clearly achievable for the theory summarised here, since all real relations are signs, and so each facet of this theory is falsifiable in principle by direct observation, once attention is turned to identifying circumstances which would produce a result either confirming or disconfirming this theory's claims. ${ }^{65}$ Moreover, since the theory is a general theory of signs, any sign serves equally as subject of observation, permitting maximal scope for its falsification, thus giving it the potential to become an especially well-tested theory. ${ }^{66}$

\section{Introducing kenosis}

With the essential characteristics of real relating thus presented, and its knowability thus understood, the grounds to introduce "kenosis" are prepared: specifically, if the direct experienceability of real relations makes them empirically verifiable in principle, then what follows will be verifiable on the same grounds, since kenosis is intrinsic to real relating.

\subsection{Relating is knowable empirically to be kenotic}

"Determining" and "representing" - the two correlated facets of relating - have what I will call a "kenotic" aspect, and to draw it out, I will need to sketch, to some minimum of detail, their modes. Relations have three modes: potential, virtual, and actual.

\subsubsection{Modes: ways of being real}

Concerning potential relations, "before" (logically speaking) any object is in relation to anything else, there is a pure, infinite array of potential relations that could form. "Potential" relations are not, however, mere possibilities of the imagination. I use the term "potential" to imply the same physical sense imparted by the term "potential energy." For example, a rock perched on the crest of a hill has a measurable potential energy, which corresponds to its mass and the height of the hill; this suffices for a new attribute - the momentum it can acquire - to be realisable with a certain definite and real "potentiality" (same sense) latent in the physical system. In other words, potentialities are engendered by the intrinsic natures of the objects relating.

64 Ibid.

65 To give a concrete example of the identification of curcumstances producing a result that would confirm or falsify a theory of this sort, I have recently exploited Powell's method to confirm divine action empirically in Culwick, "An empirically testable causal mechanism for divine action."

66 Note that while the theory presented here is empirically falsifiable, which is what distinguishes a "scientific hypothesis" from an unverifiable one, this paper does not, of course, begin the laborious task of verifying it (and neither is it required to). After all, establishing it as scientific knowledge (that is, a "theory") would require perhaps a generation of experimental scientists, rather than a single paper! What is required is a hypothesis amenable to empirical verification in order to have an advantage over an idea that is endemically speculative, and, I believe, to compel adherents to the objection against Swinburne to abandon it in favour of my theory. Relating, for example, is in principle knowable on experiential grounds to be kenotic, but without a systematic project of experimental science to generate knowledge, it will not become known to be kenotic. 
Next, consider relations between actual objects. These are actualised, as above, by some circumstance in the universe that satisfies the specific respect under which "determining" and "representing" obtain between terms. As such they are real relations. The sense in which potential attributes contrast with actual attributes is that the former are to be conceived in abstraction from any act in which they happen to be "picked out" in some subject, which would make them actual. In other words, attributes that do not currently sustain an actual relation to a quiddity are merely potential attributes. Nonetheless, potentialities are still "real" in the same sense in which people typically believe that there really are possibilities: they define what latent physical potential the universe has to change state.

As for virtuality, it is exceedingly common that a merely potential relation (or even an imaginary one) signifies actually. For example, if I am your brother, this is a real relation concerning our provenance. Now if I were to die, you would no longer have a brother. The real relation has fallen away, and only a minddependent relation to a memory and a knowledge of our common provenance remains. Yet you would continue, entirely legitimately, to refer to me as your brother, because the relation remains formally unchanged. That is, it remains founded in the same provenance, it still signifies brotherhood, and it still terminates (at least formally) at me.

In such a case, when you speak of me, your words really signify a brother to every listener, yet the terminus is now unreal, because I no longer exist. Now the definition of "virtual" is to not be some thing, yet to have the actual efficacy of that thing, ${ }^{67}$ and this is precisely the case here: the sign's terminus is unreal, that is, there is no determining correlate on the side of my quiddity, and so no real relation arises; yet everyone you speak to about me actually experiences you as signifying brotherhood. Hence, a merely potential relation signifies actually.

Note, finally, that only actualities are sufficient to establish a real relation. Potentialities are merely scenarios in which a relation could arise, while virtualities are subjective to the interpretant, even though other real relations may result from them (for example, when two people converse about one's dead brother, they really relate to one another).

\subsubsection{Modal filtering}

The three modes are derived directly from sign action: actual signs have a fundament, material terminus and interpretant, while potential signs have no interpretant, and virtual signs have no material terminus. Now when considered in terms of how things change, or how things come to be, it can be shown that they function as a modal filter. In the graph that follows, the modal filtering of relations is shown. The number of elements in the system begins with an infinite plenitude of merely virtual relations to any imaginary or otherwise unreal terminus. This number is then reduced to the latent physical potentialities that are unactualised but terminate at real things. Finally, they are again filtered, leaving only real relations - that is, interpreted relations to some material terminus. Being is thus filtered by acts of coming to be in relation.

Circled letters are attributes, rectangles are subjects, and arrows signify what a given interpretant takes a subject to signify. Interpretants (not shown) function to bring attributes from the blue circle into the domain circumscribed by the orange-brown circle, if not the green circle (Figure 6).

\subsubsection{Modal filtering and kenosis}

To manifest how modal filtering is kenotic in terms of the correlated aspects of relations introduced above, namely "determining" and "representing," I will begin by illustrating kenosis in a human and familiar setting: an act of loving. Love necessarily involves two aspects: an aspect of self-sacrifice on the part of the

67 Peirce, The Collected Papers of Charles Sanders Peirce. Electronic Edition, 6.372. See also http://www.commens.org/ dictionary/term/virtual. 


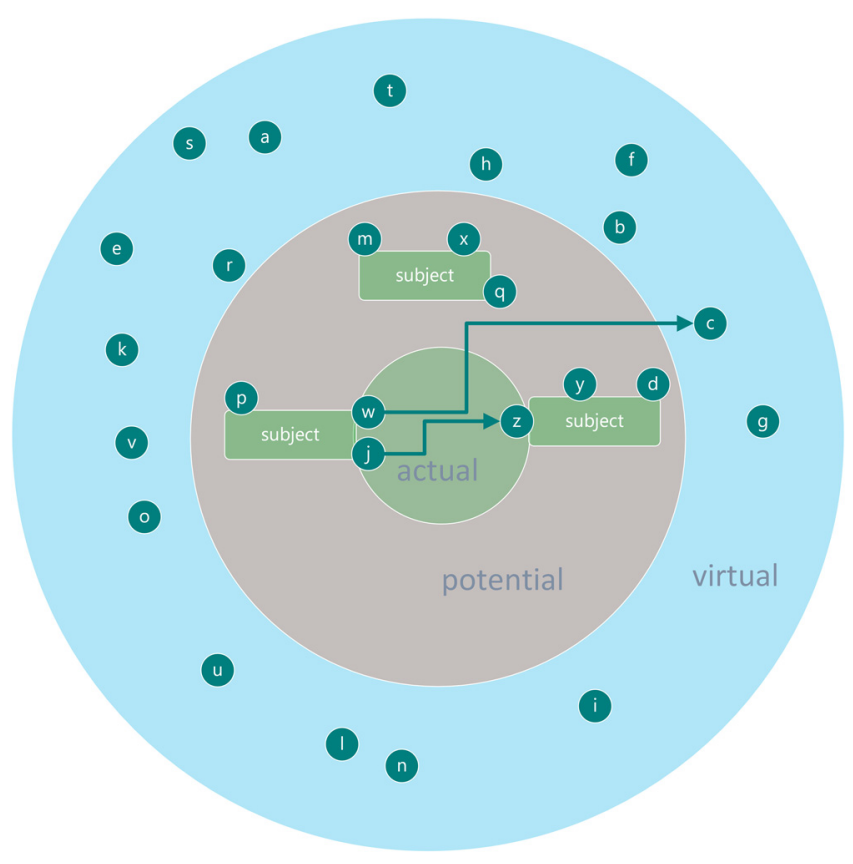

Figure 6: Modalities of relations, and their filtering effect.

lover, and an aspect of hospitality or receptivity on the part of the beloved. For example, say I take time out of a busy morning to wash the dishes for my wife. The act involves a sacrifice of my time and effort, and it involves my wife's benefitting from it. Now in order for the act to be loving, it is not only necessary for me to have done the act in love, but also for my wife to actually be loved - that is, for her good to be attained - by the act. This entails a relation characterised by determining and representing, as above: the former loves, and the latter possesses the capacity to be loved in the manner that the former loves.

It might be objected that the passive term is not necessary. For example, would it not be love even if my wife took offense, due to her feeling that I had, say, washed the dishes as if to imply that she had been neglecting them? In response I assert that my act certainly was loving, but that her good was not in fact attained, and so a real relation (that is, of the mode "actual") of loving did not occur. In other words, a loving relation of "representing" obtained from me to her, but no attribute in her was present to determine the relation, and so it was merely virtual, not actual love.

I take it to be self-evident that my sacrifice of time for the good of my wife meets the definition of "kenotic," but to bring out more clearly the nature of the passive role of "hospitality" as equally kenotic, consider a further example. You are drafted into the military for a war. The military thus designates you a soldier. If you were to accept the designation, you would exercise hospitality: you are welcoming a relation which strips your being of indefinitely many other potential designations (lawyer, priest, parent, etc.). The respect in which this is a stripping away of potentialities would be especially clear if you had an interest in a different potentiality - and especially if you did not believe in the war. Nonetheless, your being designated is not a "sacrifice" in the same sense as the active role is, since strictly speaking you are not actively giving up any potentialities. Rather, you are passive to the action of an external entity which designates you a soldier by virtue of attributes of your person determining it, like possessing legal status, age and citizenship. No action on your part is required to possess these attributes, and thus no action is required to be designated a soldier.

To clear up a potential source of confusion, when it comes to answering the call and taking up arms, action on your part is of course required, but this is consequent upon the designation, not part of it. This is clear from the fact that you would not be answering a call if you were not designated a soldier; but once designated, you are then free to play an active role by taking up arms or by objecting. Likewise, in situations where you voluntarily become a soldier without being conscripted, then you would be the active party, not 
the passive party, and your role in the relation would therefore not be one of hospitality or "determining," but of self-sacrifice or "representing."

As such, kenosis is present in both roles, because whether actively being self-sacrificial, or passively being hospitable, a stripping away of possible ways of being occurs. To be caught up in a relation of love - or of conscription, or indeed any relation at all - is to undergo modal filtering, that is, to exchange a rich array of possibilities for a limited, determinate actuality. This filtering I define as "kenosis" henceforth.

Now if you accept the earlier thought experiment about universes and relations, and the ontology of relations as briefly introduced above, then it would follow immediately that "self-sacrifice" and "hospitality" are anthropomorphic forms of the universe-wide roles of "representing" and "determining" in which the being of everything in the universe manifests kenosis. After all, to be conscripted is plainly to be the terminus in a relation of conscription, in which your imminent role as a soldier is signified, and so some of your attributes (e.g. suitable age, your giving consent) serve to determine the relation. Likewise, my washing the dishes founds a relation signifying love for my wife, and so the sacrificial act of washing represents the respect in which my wife is beloved.

As such, all being - and all experience - can be said to manifest kenosis, pervasively, in a manner analogous to acts of "self-sacrifice" and "hospitality," specifically, in acts of representing and determining.

\subsection{God is knowable speculatively to be kenotic and triadic}

Now before the problems of suffering or evil can be constructed, it requires importing speculative notions of God's existence and nature into my otherwise empirically grounded argument. Now I am not required to prove God's existence or defend his nature; rather, the problem itself presupposes these, and so I may freely assume them without the burden of proof. The actual argument may thus be entirely empirically grounded.

In the Christian tradition, God is understood on speculative grounds to be trinitarian and kenotic. To give examples: God is love English Standard Version Bible. God as Trinity is subsisting relations. ${ }^{68}$ The Spirit "proceeds from" the Father (John 15:26). A triadic relation of love characterises the trinitarian relationship. ${ }^{69}$ Christ is "the exact representation of [the Father's] being" (Hebrews 1:3). Christ is God embodied in human form. God speaks the universe into being. Jesus is "the kenosis" 70 - the perfect expression of the self-sacrificial love of God. And the nature of this kenotic expression is to live, die, and live again in a new way. Under such a wholesale protosemiosic understanding, God is clearly understood as the very essence and nature of kenosis. Moreover, God, being omnipresent, is understood to pervade the universe, and so Christians would most likely be delighted to find confirmation of this speculative idea in the empirical phenomenon of relating, which manifests kenosis at every moment and every scale of the universe.

\subsubsection{Not all kenosis is love}

From this it does not follow that all kenosis is an act of love. After all, the preceding discussion implies that kenosis is involved in the formation of atoms, and they are not capable of love, though of course their kenosis is formally analogous to loving, and on a speculative theological approach they might be supposed to participate in the divine nature to the fullest extent their natures permit, while human beings, who are capable of love, may participate to a greater degree.

68 Aquinas, Summa Theologiae, Q. 27-43.

69 Augustine of Hippo, De Trinitate, libri XV (399 and 422/6), 9.1.1.

70 This phrase stems from St. Paul's use of ekenosen (Phil 2:7) to describe the stripping of at least some of the Word's divine power when incarnated. 


\subsubsection{Reinterpreting death in the light of kenosis}

Moreover, as a result of importing speculatively grounded ideas about God, kenosis casts a new light upon the various biblical and traditional ideas concerning Christ's victory over death, for example, "death has lost its sting." "Christ conquered death."72 "Christ Jesus [...] abolished death" (2 Tim 1:10). Through the lens of sign action, it is no longer necessary to understand the traditional Christian reorientation toward death in mystical or analogical ways alone, nor only as a reference to a future bodily resurrection. Understanding Jesus's death and resurrection in terms of sign action equips Christians with a positive model of how death is conquered in the here and now, namely by it always functioning as a part of kenosis: death is always part of a "resurrection," that is, a process of new things coming to be. Not only this, but it does so in ways that are directly experienceable ubiquitously, which is a modally superior way of knowing than beliefs held on speculative grounds. That is, kenosis can be seen to "conquer" death in actual experience, not just virtually or potentially.

\subsection{Kenosis holographically signifies God}

Once the speculative notion that a kenotic and trinitarian God pervades the universe is conjoined with the empirical theory of kenosis, then it begs familiar questions: why would a theistic God create this universe? How is this universe the most perfectly good one? - or at least one in which a God unlimited by humanrelative logical necessity could create? Would it not be better to avoid there being natural disasters and interminably haphazard processes like evolution by natural selection? The number of random, unconstructive, or deleterious events could surely be reduced or eliminated.

To this I answer cursorily and speculatively by extending the earlier discussion on observed "layering" in the universe being, in fact, simply the multivalent layering operational in sign action. I speculate that a universe which embodies God's kenotic nature holographically is a more perfect embodiment than one in which God is embodied linearly or hierarchically, or in which, say, only persons embody God's nature. Now a key feature of a hologram is that each of its parts encodes the whole image embodied in it. (One can, for example, break off a small piece of a hologram, shine a light through it, and still view the complete image.) By "holographic" I recall the observation earlier that the universe is multivalently layered, and note the following in addition:

- On speculative grounds that God is omnipresent and kenotic, the universe, by being kenotic in every moment at every scale, would ubiquitously embody God's nature.

- Since every thing in the universe comes to be, or undergoes change, through sign action, and since sign action manifests kenosis, it follows that the universe is not just kenotic in its parts, but also in the relations between its parts, which themselves may come to function as further parts in further relations, indefinitely, and is thus holographic.

- In comparison to a linear or flat universe, which could only embody God's nature in one dimension, a universe in which all its parts, and all its relations between parts, which themselves may come to function as further parts in further relations, embody God's nature in an indefinite number of dimensions. For example, when something at a higher layer (e.g. a person) functions kenotically, and all its parts (e.g. atoms) do too, as well as the respect in which the atoms constitute the person, then the kenotic nature of the universe is compounded exponentially.

Without yet providing an answer to why God might permit natural disasters and so forth, I believe that a metaphysics of sign action suggests a cursory answer to why a theistic God would create this universe rather than some other one: a universe that best embodies God's nature is one that is holographically kenotic.

71 This common phrase is derived from 1 Cor 15:56 (English Standard Version Bible).

72 This phrase typically refers to Jesus's resurrection. 


\subsection{Kenosis in human contexts involves the experiences of suffering, evil, and death}

More fundamentally, kenosis comes to bear upon theodicy by taking suffering or death to be, at bottom, a loss of possibilities. While all being and becoming involves kenosis, sometimes what is lost defeats our hopes or intentions, or troubles our worldview, and it is in these instances that we may experience suffering, death, or come to perceive something as evil. For example, newlyweds may discover that the high cost of marriage is in no longer being a self-defining individual, and must instead reshape their purposes, habits, and priorities in collaboration with their partner. New parents sacrifice sleep, hobbies, and the flexibility of their time to raise a baby. At death, the kenosis of one's bodily function eventually ceases to sustain personhood, leaving only the lower-layer kenosis of biological chemistry to continue on. When a volcanic eruption destroys a town, then the loss of potential is very great, and it can be difficult to reconcile this loss with a belief in a perfectly good God, even if the underlying physical process is thoroughgoingly kenotic. It is to this sort of problem that I now turn. In each of the above cases, potentialities that matter to us are lost when some reality is actualised. This, according to the relational cosmology sketched in Section 3, is the ground of suffering, evil, and death. That is, it is where the problems of suffering and of evil provenate.

\subsubsection{Kenosis does not permit conceiving of suffering, evil, or death as real natures}

The relational light I have shone on this problem puts in empirical form Augustine and Aquinas's view that it would be a mistake to speak of suffering or evil as the real nature of anything. To do so would be equivalent to saying that being-to-the-left is a real property in abstraction from whatever is to its right. Rather, the kenotic process of living, dying, and living anew (to put it anthropomorphically) locates suffering or evil at "dying," which (to put it technically) is always part of a process of becoming a correlate in a new relation. As such, it would be false that suffering or evil exists as an independent nature. Therefore, "evil" taken in isolation is unreal. It is a misperception to consider suffering, death, and evil outside of kenosis.

\subsection{2 "Death" is part of loving}

The observation that kenosis implies that suffering, death, and evil are an essential part of the kenotic process - and in anthropocentric contexts, part of loving - recasts the problems of evil and of suffering, and suggests a bold resolution to the principal problem faced by traditional theodicies, namely how it can be possible for a theistic God to permit both suffering (or evil) and our free will. While traditional theodicies do not satisfactorily answer why a theistic God did not simply create a universe in which this problem does not arise, a kenotic theodicy may answer that empirical experience compels us to reconstrue suffering and death as essential parts of loving, and thus that kenosis is the real nature, while death or suffering construed in isolation from kenosis are unrealities. As such, theodicy appears no longer to be a dilemma between God's omnipotence and omnibenevolence, but rather a dilemma between our holding fast to an ideological commitment ordered to the purpose of solving a speculatively grounded problem, and our becoming open to God's kenotic nature in us and all around us, and consequently allowing our conceptions of love and of theodicy to be moulded by God through the signification of anything in the universe. This theodicy is thus a transformation of stance from a first-personal one to a second-personal one ${ }^{73}-\mathrm{a}$ transition from "knowledge-that" to Franciscan knowing.

73 I owe this insight to Andrew Pinsent, who in The Second-Person Perspective in Aquinas's Ethics, interprets Aquinas's understanding of the virtues to be second-personal, that is, to be attributes of how one relates to another person, not the first-personal habituated attributes of Aristotelian virtue theory. Moreover, Pinsent presents Aquinas's account of the beatitudes as having a narrative dimension, serving to facilitate a movement from first-personal to second-personal orientation (specifically, they "encourage the virtue of hope [which has a first-personal goal] in such a way as to lead to the maturing of love," which has a second-personal goal). (Ibid., 91.) 


\subsection{The fall of Jericho}

Now at this point a sceptic might object that my approach fails to support sufficiently the claim that God is perfectly good, because regardless of what I have said, it remains the case that God's kenotic nature is partly to inflict suffering upon the world. However, such a move appears to me to have an idealistic preference for founding morality upon unrealities, especially when we have, on the side of the real, a continual and ubiquitous experience of kenosis available to us. To resort again to "Franciscan knowledge," the objector appears to me to take the stance of Joshua when he comes to Jericho. He seeks to impose upon God an unreal conception of goodness, when the fundamental functioning of the entire universe compels him not to mistake parts for wholes, and instead to allow his understanding of goodness to be formed by the actual, kenotic, nature of love. All the universe is our messenger from the LORD, and the message is to abandon idealism and conform our understanding to what is real and empirically knowable, and in so doing to exercise the very hospitality operational in kenosis, further advancing the apparently holographic evolution of the universe.

\subsection{Co-creators with God}

Perhaps my objector would now attempt a different attack. I have not denied that we have free will; hence, presumably, we are capable of choosing to act either kenotically or antikenotically. Would this not limit either God's omnipotence, omnipresence, or omnibenevolence? After all, the presence of antikenotic action in the universe ostensibly implies a respect in which God is not present, where the universe is not a perfect embodiment of Their nature, and in which it is thus possible for evil to be not just an aspect or part of kenosis, but a positive whole in its own right.

I deny the conclusion. The presence of kenosis is modally different from the presence of anything subordinate, like whether a rock is here or there, or whether a person acted generously or not. Rather, kenosis is simultaneous with being, and so either there is nothing, or there is kenosis. Now while I do not intend to eliminate or otherwise minimise the experience of suffering or of evil, at this point in the defence it is necessary to be categorical. Recall the thought experiment given earlier concerning universes: if two things are not in relation in any respect, then they are not part of the same universe. The same follows for the hypothetical notion of "antikenosis:" as a principle of nonrelation, it is unreal.

\subsubsection{Evil and suffering are real virtually}

That said, when a person does evil, it is obvious that the person is part of the universe, and so the person's act is also part of the universe, at least insofar as it has an effect, and so it does not appear prima facie unreal. It is to the modelling of this that I now turn. When a person does evil, there will be some aspect either of that person or of the world, or of some relation between the two - that is indeterminate. That is, when acting in this way, the person may not function as an organic whole in their own right, and so there would be a respect in which a person is unreal. (An analogous situation would apply when the indeterminacy is in the world.) For example, if I were to vindictively push you down a flight of stairs, this could perhaps be because I am overcome by jealousy. You thus come to signify to me the object of my jealousy, when in your intrinsic nature you are quite distinct and, furthermore, may not personally identify with whatever it is that I perceive in you. As such, I construct a virtual sign, since there is no attribute really signified by the formal terminus of my construction. Yet, true to virtual signs, this virtuality has a real effect, namely of prompting me to violence. It is in this manner that evil and suffering can be modelled using sign action: as unrealities that are actually signified by virtual signs, so that the interpretant (my pushing you down the stairs) is informed by the virtual sign and thus - to observers and (probably) to my jealous self - is informed by the unreal nature of its terminus and in such a way appears as a positive evil in its own right. 
But it is not a positive evil in its own right, it is a real act construed in terms of an unreality. Consider the scenario in terms of abstraction layers: it is again not the case that interpersonal relating can be antikenotic, because any relation that exists is kenotic. Rather, when someone does evil to another person, they establish a relation that functions kenotically, but only at a lower layer, which unmakes something kenotic at a higher layer. In terms of how the other person is treated, the evil actor's behaviour is marked not by an antikenotic relation, but by a disturbing absence of relation at a layer where we would strongly desire a relation to obtain.

To remain consistent with how this theory handles indeterminacy, such situations are modelled to lie on the fringes of a still-forming universe, where the entities interacting do not determine each other in certain respects. Namely, simultaneously we find ourselves strongly motivated to form kenotic relations at this higher layer, but we also encounter people who are not unified in the requisite respects and either cannot perceive, or come to desire, or come to put in place, the requisite relation at the requisite layer.

\subsubsection{Virtualities have actual effects}

To further unpack the nature of virtual signs, note that the act of pushing is, in itself, not formally a locus of evil, but a real and kenotic act, at least at the layer at which it operates (I may, for example, play games with friends of mine in which we playfully push each other down a flight of stairs, and the act of pushing supports this higher layer equally alongside my violent act). However, what is perhaps most jarring in the act is how the virtual sign functions to twist the underlying goodness of the act's kenotic nature (e.g. as converting potential energy to kinetic energy) to an evil end. It is to this disturbing aspect that we now turn, at which my objector may justifiably sound the alarm along the following lines: "if virtuality can essentially prey upon a kenotic universe, limiting its goodness by exploiting its indeterminacy, then God ought not create gaps in the universe's determinacy!”

I cautiously disagree. I think that, firstly, the main force of this objection comes from a desire for the universe to manifest goodness perfectly at every layer (a desire which I share). However, it is false that a perfectly good universe must have no "gaps.” After all, as Figure 1 demonstrates, there being no "gaps" implies that there can be only one thing, removing the possibility of a universe entirely - never mind one that holographically embodies God's kenotic nature. Moreover, the objector would be unable to claim that this brings my objection to Swinburne to bear with equal severity upon this argument, because the actual nature of the universe should inform our notion of goodness, rather than our letting idealistic predilections hold sway.

In addition to serving to ward off idealism, the observed reality of indeterminacy can play a moral or perspectival role. My objector's alarm does not tend to be sounded only at the presence of "gaps." Suicides, fatal acts of bravado, disasters of many kinds, and so forth draw similarly indignant responses. However, if I were foolhardy enough to jump off a building in the hope that God would make an exception to the laws of nature in order to save me, this may be a "gap" in the sense that it exhibits insufficient determinacy in respects necessary to guarantee my thriving, but it is also a case of routine continuity of the lawlike and kenotic functioning of the universe. As such, it is modelled as the same sort of direct-experiential force that I have argued compels a "Franciscan" change of stance toward theodicy: we are primarily subject to God's universe, and would do well to be taught by it, rather than proceeding on speculative grounds impervious to reality. "Gaps" are to be known, respected, and where it is within our power, to be closed, treated with due caution, or otherwise protected against.

\subsubsection{Our primary purpose}

If my objector were to then remark

this is not what I mean - I do not mean total relationality, in which there can be only one thing - I just mean that there ought to be the usual sort of layered kenosis everywhere, but in a determinately perfect state, not an indeterminate state. For example, the nature of the universe ought to faithfully guide people to do good. If the universe lacks this, then it is deeply flawed in this respect at this layer. 
I answer that, firstly, such "gaps" are what appear, empirically, to permit kenosis to compound holographically. They are the mark of an active, evolving kenotic expression or process, which would not be possible in a universe consisting of a changeless, static collection of properties. After all, kenosis requires a filtering from the virtual or potential to the actual: something must always lose a rich array of possibilities for the actual to emerge, or else there is no kenosis. On this ground, the desire for a fully determinate universe looks idealistic, not empirically grounded, and should be abandoned in a "Franciscan" change of stance.

That said, I cannot rule out the possibility that I have failed to imagine some equally empirically grounded model in which every layer is determinately perfect, or is maximally kenotic in another, more perfect way than the "holographic" conception employed in this article. However, on the one hand, it is not clear what could comprise a more kenotic universe, and on the other, if some promising new conception were to arrive, nothing in principle prevents this theory from being reconstrued in its light instead of in "holographic" terms.

Provisionally, then (that is, under the rubric of holographically compounding kenosis), there emerges a second moral or perspectival part of this solution to the problems of suffering and evil: cases of "gaps" are partly within our power to work to perfect, and, at a second order, are within our power to improve our power to perfect. That is, while kenosis is pervasive, at newly forming and partially indeterminate higher layers, we may want to resolve certain parts to determinacy so that a person's actions better preserve other higher-order things in the universe (like virtuous relationships). In such a scenario, we may enjoy the inestimable privilege of being co-creators with God, where we recognise, with God, the good, and work to achieve it. ${ }^{74}$ In the respect that this co-creating is the universe coming to recognise its creator's nature and wishes, it represents the very pinnacle of creation. For a kenotic God to be embodied not only in kenotic action on the part of God's creations, but for some of them (namely human beings) to know and love God for what God is, and to kenotically work to cause new kenotic layers to arise, may be the highest perfection yet to emerge in the universe (thus far). I certainly find it difficult to imagine a richer compounding of kenosis.

\subsection{Further objections}

\subsubsection{Mind games?}

A final objection: could this resort to "holographic layering" not just be a mind game? After all, there is a well-known aphorism in computer science that any problem may be solved with the use of an abstraction layer. How then might one distinguish this theory from the mistaken theory of epicycles? How are unreal mental gymnastics distinguished from the tracking of the truth?

I respond that layers - and their holographic compounding - are distinguished in the actual functioning of real things, insofar as reality is available to direct experience. Specifically, we experience real relations directly, and can converge on the functioning of real things by systematically testing theories, until a scientifically confirmed model results. My theory is falsifiable on these grounds: find a person doing evil; experimentally confirm the real relations at play; if the relations cannot be constructed in terms of sign action, then they are antikenotic and the theory is falsified.

\subsubsection{Problems specific to wandering in darkness}

I believe that this theory is able to provide solutions to the four problems Paul Draper notes in his review ${ }^{75}$ of Wandering in Darkness. ${ }^{76}$ Specifically, he notes that it is difficult to see how Stump's argument accounts for

74 I owe this way of conceiving of love second-personally to Pinsent, The Second-Person Perspective in Aquinas's Ethics, (71, 91), without which I would not have identified kenosis with the second-personal virtue of love.

75 Draper, “(Review) Wandering in Darkness: Narrative and the Problem of Suffering.” 
(a) suffering which predictably diminishes the sufferer or (b) natural disasters that indiscriminately affect people, when the healing of individual psychological fragmentation is the goal of suffering on Stump's account; (c) how trivial suffering (like scraping one's shin) could aid sanctification; and (d) why humans and animals suffer similarly, when animals seem incapable of undergoing a process of justification and sanctification.

Now if we are called to be (and to grow as) co-creators with God, I believe this resolves (a), (b), (c), and (d) in one fell swoop, because, firstly, if kenosis is an embodiment of God's nature, then our acting to prevent all of these, through compassion and through technological innovation, would be how kenosis is present in these events, and how it evolves holographically, and simultaneously how God is acting to bring about greater and greater good, in a universe that is capable of compounding kenosis indefinitely. Secondly, to bring about kenosis is to create realities on the fringes of the universe, wherever it is marked by unstably kenotic indeterminacy or unreal "gaps." These two facets taken together mean that it is never the case that kenosis is not pervasive in the universe, and that our ability to further weave kenosis at higher layers is partially how the universe is capable of compounding kenosis indefinitely - especially in the respect that our second-personal, loving co-creation with God may embody the current pinnacle of creation.

\section{Resolution to the problems of evil and of suffering}

Thus is my Franciscan turning of the tables. Could God have done otherwise? Yes of course, but for this to happen, God would be different to what God is. "God is love"77 would not mean what it means. We are "stuck with God," so to speak, and we would be foolish to depart into idealism from what the real presents us with when defining the good.

We thus no longer need wonder why a "good" God (merely speculatively defined) can allow suffering (myopically understood in alienation from love, of which it is a part). Instead, we may see empirically the God who is love and involves kenosis in Their own being, and conform our understanding of goodness to reality.

To resolve the problems of evil or suffering, then: the traditional account contains an "inconsistent set" consisting of God's perfect goodness, omniscience, and omnipotence, alongside human freedom and the presence of suffering, evil, or death. Armed with the action of signs, my claim as to their universality, and Powell's relational-realist methodology of science, I provide grounds for testing for the reality of a universe in which the "inconsistent set" does not arise. Specifically, it is claimed that kenosis can be observed to operate in various scenarios which typically cause the inconsistent set to arise (e.g. moral and natural evils), but that when attention is paid to the kenotic workings of sign action, the inconsistent set does not arise. In a little more detail, this theodicy takes a three-pronged approach to the resolution of this set:

(1) The "Franciscan" turn: it relies on an appeal to direct experience to inform our "right-brain" conceptions of God's nature and of the universe, in order to manifest kenosis. This is employed both in this article's approach to theodicy itself, and in the importance of being attuned to the nature of a kenotic world. For example, it takes a special kind of arrogance to jump off a building and hope that God will modify the law of gravity to save you. We are compelled to recant idealism in order to understand our place in the world.

(2) The modal dynamic: kenosis involves death or suffering as a necessary part, and so they cannot be constructed as isolated events separate from the "new life" that they are ordered to. In more detail, they are unrealities signified by virtual signs, and represent "gaps" or areas of indeterminacy where the universe is relatively unformed and amenable to compounding kenosis at a new layer.

(3) The telos: where virtual signs have actual and deleterious effects, or where indeterminacy fails to secure kenosis in respects that matter to us, then in addition to serving to compel us toward (1), it permits the

76 Stump, Wandering in Darkness.

77 English Standard Version Bible, 1 John 4:8. 
universe the capacity to compound its kenosis indefinitely, notably, for the purposes of human flourishing, through our coming to know and love, with God, what God loves. In this latter instance, kenosis is not only embodied in our relating to God, but also in the higher-order mode where we may recognise the kenotic aspect of our relating and intend it deliberately, which forms a yet-higher kenotic layer in the universe. It is through such processes that the universe comes to compound its kenosis, making it capable of indefinite perfection.

Indeed, if love is the greatest virtue and "unites everything in perfect harmony," 78 and Christ - the kenosis - really has "abolished death" ( 2 Tim 1:10), then we should expect to identify this empirically. If I am correct, this theodicy does so, resolving the "inconsistent set" - and not in a merely speculative way (which is trivial to accomplish) but in an empirically grounded way secured by direct experience. ${ }^{79}$

\section{References}

Aquinas, Thomas. Summa Theologia. Benziger Bros. edition. Translated by Fathers of the English Dominican Province, 1947 (1266-1268). https://dhspriory.org/thomas/summa/FP/FP005.html\#FPQ5A2THEP1.

Aquinas, Thomas. Summa Theologiae, edited by Roberto Busa. Vol. 2. 7 vols. Stuttgart-Bad Canstatt: Frommann-Holzboog, 1980 (c. 1266/73).

Augustine of Hippo. "City of God." In Nicene and Post-Nicene Fatheres: Series 1, Volume II, edited by Philip Schaff and Kevin Knight. Translated by D.D. Rev and Marcus Dods. Buffalo: Christian Literature Publishing Co, 1886 (5th C.). Accessed 0712 , 2019. http://www.newadvent.org/fathers/1201.htm.

Augustine of Hippo. Enchiridion: On Faith Hope, and Love, edited by Albert C. Outler. Translated by Albert C. Outler. 1955 (420). Accessed 07 12, 2019. www.tertullian.org/fathers/augustine_enchiridion_02_trans.htm\#.

Augustine of Hippo. De Trinitate libri XV. Vol. L \& La VII. In Corpus Christianorum Series Latina, edited by W. J. Mountain and Francois Glorie. Turnholt: Brepolis, 1968 (399 and 422/6).

Culwick, Arlyn. “How Sign Action Really Works.” Academia.edu 2018. 06 09. Accessed 09 06, 2018. https://www.academia. edu/37353759/How_Sign_Action_Really_Works.

Culwick, Arlyn. ““Machine code for the universe:” how the action of signs pervades everything.” Academia.edu 2019.1703. Accessed 07 14, 2019. https://academia.edu/39709311/_Machine_code_for_the_universe_-_how_the_action_of_signs_ pervades_everything.

Culwick, Arlyn. "An empirically testable causal mechanism for divine action.” Academia.edu, 2019. 30 08. Accessed 08 30, 2019. https://academia.edu/.

Culwick, Arlyn. "How To Render Freedom Empirically Verifiable: Ralph Austin Powell's Radically Scientific Thomism.” Academia.edu 2020. 24 03. Accessed 04 01, 2020. https://www.academia.edu/38466994/How_To_Render_Freedom_ Empirically_Verifiable_Ralph_Austin_Powells_Radically_Scientific_Thomism.

Cummings, E. E. Complete Poems 1904-1962, edited by George James Firmage. New York: Liverright Publishing Corporation, 1992.

Draper, Paul. "(Review) Wandering in Darkness: Narrative and the Problem of Suffering.” In Notre Dame Philosophical Reviews, edited by Anastatia Friel Gutting. 2011. Accessed July 10, 2019. https://ndpr.nd.edu/news/wandering-in-darknessnarrative-and-the-problem-of-suffering/.

English Standard Version Bible. Wheaton: Crossway Bibles, 2001.

Geertz, Clifford. "Thick Description: Toward an Interpretive Theory of Culture.” In The interpretation of Cultures: Selected Essays, 3-30. New York: Basic Books, 1973.

Hawking, Stephen. A Brief History of Time: from the Big Bang to Black Holes. New York: Bantam Books, 1988.

Hofstadter, Douglas. I Am a Strange Loop. New York: Basic Books, 2007.

Huang, Rongxin, Chavez, Isaac, Taute, Katja M., Lukić, Branimir, Jeney, Sylvia, Raizen, Mark G., and Florin, Ernst-Ludwig. “Direct Observation of the full transition from ballistic to diffusive Brownian motion in a liquid." Nature Physics 7 (2011), 576-80. Accessed 07 14, 2018. http://www.nature.com/nphys/journal/v7/n7/full/nphys1953.html.

78 English Standard Version Bible, Col 3:14.

79 First delivered at the Ian Ramsey Centre’s conference, “Compassion and Theodicy,” Oxford University and Eynsham Hall, 20 July 2019. I am grateful to Eleonore Stump for her remarks following the presentation of the initial version of the article, and to James Taddeo for writing to ask my opinion on questions related to this theodicy, which aided me in clarifying certain ideas. 
Lewis, C. S. Mere Christianity. New York: Harper Collins, 1952.

New American Standard Bible. Nashville: World Publishing, 1995 (1960).

Peirce, Charles. Lowell Lectures on The Logic of Science; or Induction and Hypothesis: Lecture VII, 1866.

Peirce, Charles Sanders. The Collected Papers of Charles Sanders Peirce. Electronic Edition, edited by Charles Hartshorne and Paul Weiss. Cambridge, MA: InteLex Corp, 1994 (1958-1966). Accessed 09 06, 2018.

Pinsent, Andrew. 2012. The Second-Person Perspective in Aquinas's Ethics. New York: Routledge.

Pironio, S., Acín, A., Massar, S., Boyer de la Giroday, A., Matsukevich, D. N., Maunz, P., Olmschenk, S., et al. "Random numbers certified by Bell's theorem." Nature 464 (2010), 1021-2024. Doi: 10.1038/nature09008.

Plantinga, Alvin. God, Freedom and Evil. New York: Harper and Row, 1974.

Poinsot, John. Tractatus de Signis, edited by John Deely and Ralph Austin Powell. Berkeley: University of California Press, 1985 (1632).

Powell, Ralph Austin. Freely Chosen Reality. Washington, DC: University Press of America, 1983.

Powell, Ralph Austin. "From semiotic of scientific mechanism to semiotic of teleology in nature." Semiotics (1986), $296-305$. Powell, Ralph Austin. “Epistemology's Minimal Cause as Basis of Science.” In Semiotics 1988, edited by Terry Prewitt, John Deely and Haworth Karen, 180-8. New York: University Press of America, 1989.

Ryle, Gilbert. “The Thinking of Thoughts: What is 'Le Penseur' Doing?” Internet Archive: Wayback Machine 1968. Accessed 08 30, 2020. https://web.archive.org/web/20141221022028/http://lucy.ukc.ac.uk/CSACSIA/Vol14/Papers/ryle_1.html.

Stump, Eleonore. "The Problem of Evil." Faith and Philosophy 2:4 (1985), 392-423.

Stump, Eleonore. Wandering in Darkness: Narrative and the Problem of Suffering. Oxford: Oxford University Press, 2010. Swinburne, Richard. Providence and the Problem of Evil. Oxford: Clarendon Press, 1998.

The Computer Language Company Inc. "abstraction layer" 1981-2013. Accessed 07 13, 2014. http://encyclopedia2. thefreedictionary.com/abstraction+layer. 